\title{
RANCANG BANGUN SISTEM INFORMASI JASA PEMBUATAN PAKAIAN DENGAN ALGORITMA PEMPROGRAMAN TERSTRUKTUR
}

\author{
Jauhari Maulani ${ }^{1)}$ Muhammad Amin ${ }^{2)}$ \\ Fakultas Teknologi Informasi, Universitas Islam Kalimantan Muhammad Arsyad Al Banjari Banjarmasin \\ Email : jauharimaulani@gmail.com \\ Fakultas Teknologi Informasi, Universitas Islam Kalimantan Muhammad Arsyad Al Banjari Banjarmasin \\ Email : maminbjm58@gmail.com
}

\begin{abstract}
Abstrak
Pembuatan pakaian diperuntukan untuk dipakai kegiatan sehari -hari, untuk acara atau untuk pakaian seragam baik perkantortan atau komunitas. Pada setiap harinya para pelanggan datang untuk membuat pakaian pada butik jasa pembuatan pakaian husnah busana. Para pelanggan di data dengan cara dicatat data diri dan data ukuran pada pembukuan secara tulis tangan, buku catatan makin menebal dan makin bertumpuk banyak data dari para pelanggan yang telah dicatat. Pada pelanggan yang sudah pernah di data namun pada sewaktu waktu pelanggan kembali membuat pakaian, pencarian data sulit dilakukan dengan pencarian di catatan pembukuan, membuka lembar - lembar kertas data pelanggan yang sudah ada. perlunya sistem yang terkomputerisasi untuk mempermudah pelayanan pendataan pelanggan dan proses transaksi pelayanan jasa pembuatan pakaian pada butik husnah busana. aplikasi sistem informasi jasa pembuatan pakaian yang akan dirancang dan dibangun dengan menerapkan algoritma pemprograman terstruktur agar lebih mudah dalam pembuatannya dengan struktur logika yang benar dan mudah dipahami serta menyederhanakan kerumitan program. Rancang bangun sistem informasi yang di telah dibuat dapat membuat pendataan dan transaksi lebih cepat serta efektif dan efisien.
\end{abstract}

Kata Kunci: Sistem Informasi, Algoritma, Pemprograman Terstruktur.

\section{PENDAhuluan}

Pakaian sudah menjadi kebutuhan orang - orang dimasa sekarang, setiap harinya pakaian baik baju ataupun celana selalu diproduksi. Pembuatan pakaian diperuntukan untuk dipakai kegiatan sehari -hari, untuk acara atau untuk pakaian seragam baik perkantortan atau komunitas. Pada setiap harinya para pelanggan datang untuk membuat pakaian pada butik jasa pembuatan pakaian Husnah Busana. Para pelanggan di data dengan cara dicatat data diri dan data ukuran pada pembukuan secara tulis tangan, buku catatan makin menebal dan makin bertumpuk banyak data dari para pelanggan yang telah dicatat.

Pada pelanggan yang sudah pernah di data namun pada sewaktu waktu pelanggan kembali membuat pakaian, pencarian data sulit dilakukan dengan pencarian di catatan pembukuan, membuka lembar - lembar kertas data pelanggan yang sudah ada. Terkadang data pelanggan tidak ditemukan, disebabkan oleh pergantian pembukuan atau hilangnya kertas data pelanggan, untuk pencarian memerlukan waktu yang cukup lama.Selain itu data hasil setiap transaksi tidak terkontrol karna tidak adanya penghitungan, sulitnya untuk mengaetahui hasil transaksi yang telah dilakukan baik harian ataupun bulanan.

Berdasarkan latarbelakang masalah yang telah ada, maka perlunya sistem yang terkomputerisasi untuk mempermudah pelayanan pendataan pelanggan dan proses transaksi pelayanan jasa pembuatan pakaian pada butik Husnah Busana. Rumusan masalah yang akan dicapai pada penelitian ini yaitu bagaimana merancang bangun aplikasi sistem 
informasi jasa pembuatan pakaian dapat membantu mempermudah setiap pendataan dan transaksi denagan baik.

Pembuatan sistem yang terkomputerisasi dilakukan dengan membuat perintah dengan menuangkannya kedalam bahasa pemprograman, aplikasi sistem informasi jasa pembuatan pakaian yang akan dirancang dan dibangun dengan menerapkan algoritma pemprograman terstruktur agar lebih mudah dalam pembuatannya dengan struktur logika yang benar dan mudah dipahami serta menyederhanakan kerumitan program.

Oleh karena itu perencanaan pada penelitian ini merancang bangun sistem informasi jasa pembuatan pakaian pada butik husna busana dengan menerapkan algoritma pemprograman terstruktur, dengan tujuan penelitian ini agar sistem informasi mempermudah menginput dan mencari data pelanggan serta pelayanan transaksi pada toko jasa pembuatan pakaian.

\section{METODE PENELITIAN}

\section{Sistem Informasi}

Informasi adalah data yang telah diolah menjadi sebuah bentuk agar sistem informasi mempermudah menginput data pelanggan dan pelayanan transaksi pada toko jasa pembuatan pakaian.yangh berarti bagi penerimanya dan bermanfaat dalam mengambil keputusan saat ini atau mendatang (Davis, 1995). Mc Leod (1995) mengatakan bahwa informasi adalah data yang telah diproses, atau data yang memiliki arti. Sistem Informasi Manajemen (SIM) dapat didefinisikan sebagai suatu alat untuk menyajikan informasi dengan cara sedemikian rupa sehingga bermanfaat bagi penerimanya (Kertahadi, 1995). Tujuannya adalah untuk menyajikan informasi guna pengambilan keputusan pada perencanaan, pemrakarsaan,pengorganisasian, pengendalian kegiatan operasi subsistem suatu perusahaan dan menyajikan sinergi organisasi pada proses (Murdick dan Ross, 1993).

\section{Algoritma}

Ada beberapa definisi algoritma diantaranya adalah :

1) Algoritma adalah penyusunan langkahlangkah penyelesaian masalah dalam bentuk kalimat dengan jumlah kata terbatas tetapi tersusun secara logis dan matematis.

2) Algoritma adalah suatu prosedur yang jelas untuk menyelesaikan suatu persoalan dengan menggunakan langkah-langkah tertentu dan terbatas jumlahnya.

3) Algoritma adalah susunan langkah yang pasti, yang bila diikuti maka akan mentransformasi data input menjadi output yang berupa informasi.

\section{Pemprograman Terstruktur}

Pemrograman Terstruktur (Structured Programming) mengacu dari suatu kumpulan tehnik yang dikemukan oleh Edsger Dijkstra, dengan tehnik ini akan meningkatkan produktifitas programmer, dengan mengurangi waktu yang dibutuhkan dalam penulisan (write), pengujian (test), penelusuran kesalahan (debug) dan pemeliharan(maintain) suatu program. Pada pembahasan berikut ini kita akan melihat bagaimana tehnik ini yang pendekatan yang dilakukan secara modular, dapat membantu kita dalam membangun suatu program.

\section{Metode WATERFAL}

Siklus Pengembengan Sistem Informasi atau System Development Life Cycle (SDLC) yang identik dengan istilah metode air terjun (Waterfall Method). 


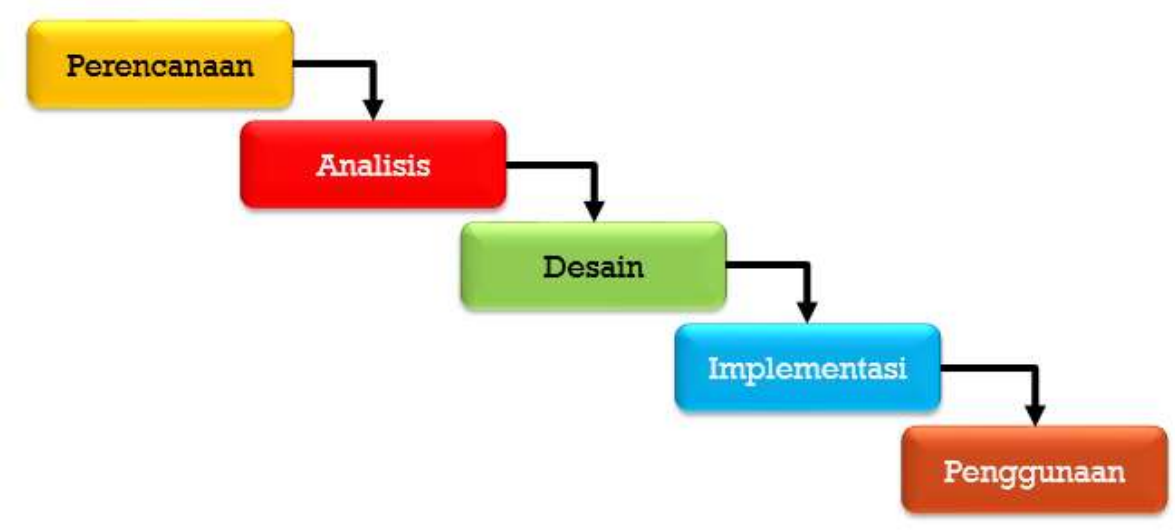

Gambar 1.Tahapan Metode Air Terjun (Waterfall Method)

\section{Perencanaan}

Pada tahap ini peneliti melakukan identifikasi masalah lebih dalam. penentuan masalah yang telah ditemui, adanya data pelanggan yang tertumpuk karna sistem dilakukan dengan pencatatan pada kertas pembukuan, pencarian data pelanggan yang sulit dari lembar pembukuan dan pemberitahuan estimasi penyelesaian pembuatan pakaian.

Dari masalah yang telah ada, maka perlunya menganalisis dan merancang sistem informasi yang memudahkan dalam proses pendataan, pencarian data pelanggan, transaksi dan pemberitahuan estimasi penyelesaian pada jasa pembuatan pakaian.

\section{Tahap Analisis}

Tahap analisis perluanya identifikasi atau investigasi yang lebih mendalam untuk mengkaji sistem agar memperoleh data yang diperlukan dalam penyusunan penelitian ini, dengan menggunakan metode pengumpulan data sebagai berikut:

1. Wawancara atau interview melakukan tanya jawab langsung kepada pihak butik Husna Busana tentang bagaimana alur sistem yang sedang berjalan pada tempat tersebut guna analisis untuk membangun sistem informasi pada penelitian ini.

2. Pengamatan Langsung atau Observasi. Mengamati langsung proses pengumpulan data yang telah dilakukan oleh pihak butik pada umumnya.

3. Studi Pustaka Pengumpulan data dengan menggunakan buku-buku dan pencarian di internet sebagai bahan referensi dalam penulisan laporan dan pembuatan sistem.

Dari hasil analisis yang dilakukan secara wawancara dan pengamatan langsung maka dapat lebih diketahui tentang bagai mana sistem yang berjalan yang ada pada butik husna busana agar bisa membentuk analisis kebutuhan sistem yang akan dibangun dalam perancangan membangun sistem informasi jasa pembuatan pakaian dengan algoritma pemprograman terstruktur.

\section{Perancangan Alur Sistem Informasi}

Perancangan sistem informasi secara terperinci, diperlukan untuk mengetahui arah kemana saja alur sistem program serta pendistribusian data yang dipakai untuk pembuatan sistem informasi. Berikut diagram alur data pada perancangan sistem informasi jasa pembuatan pakaian dengan algoritma pemprograman terstruktur : 


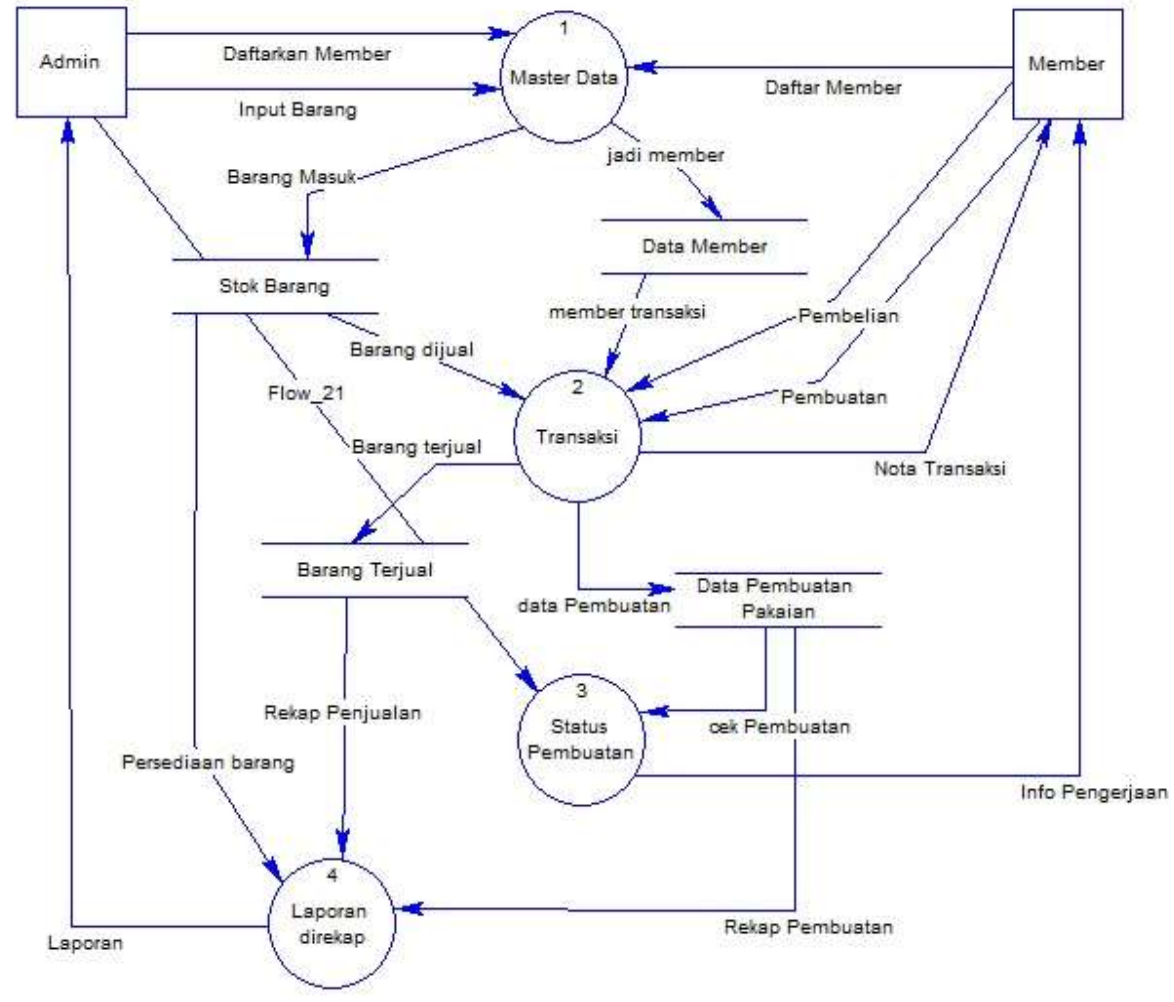

Gambar 2. Diagram Alur Data

Dari diagram alur data diatas sistem dikelola oleh admin butik yang bisa menambahkan pendaftaran pelanggan, data diri dan ukuran pelanggan, pelayanan proses pemesanan dan pemberitahuan progres pembuatan pakaian serta transaksi pada sistem informasi. Pendaftaran dan pemesanan juga bisa dilakukan oleh member, serta informasi progres melalui notifikasi yang didapat oleh member.

\section{HASIL DAN PEMBAHASAN}

\section{Implementasi}

Tahap implementasi sistem ini dilakukan penerjemahan algoritma hasil analisis dan perancangan sistem informasi jasa pembuatan pakaian kedalam bahasa pemprograman yang terstruktur untuk diimplemtasikan menjadi sebuah sistem informasi atau aplikasi yang bisa digunakan dengan komputer, laptop ataupun handphone.

\section{Tampilan Antar Muka Aplikasi}




\section{Tampilan Input Data Member}

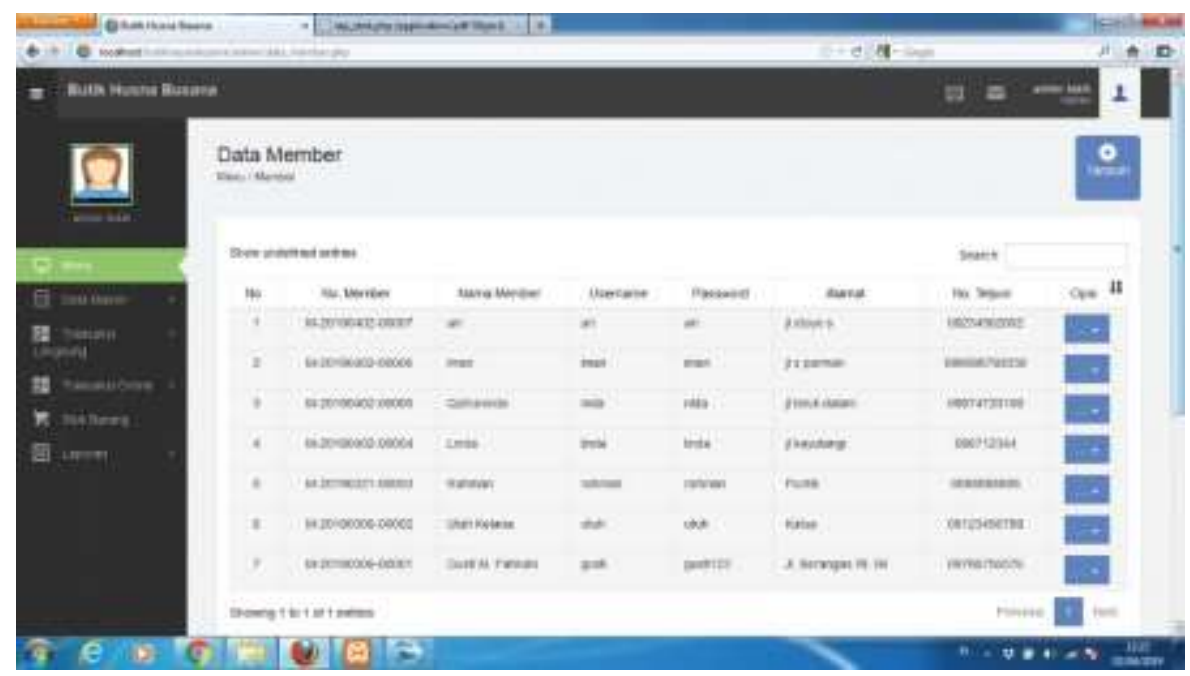

Gambar 3. Form data member

Pada halaman data member ini digunakan untuk mendata data diri dan kontak para pelanggan butik husna busana dan adanya kolom pencarian berguna mempermudah pencarian data pelanggan atau member. Pendataan member bisa dilakukan oleh pelanggan sendiri dengan melakukan pendaftaran dari website sisten informasi butik husna busana atau juga bisa didaftarkan oleh admin dari butik husna busana.

\section{Tampilan Data Ukuran Pelanggan}

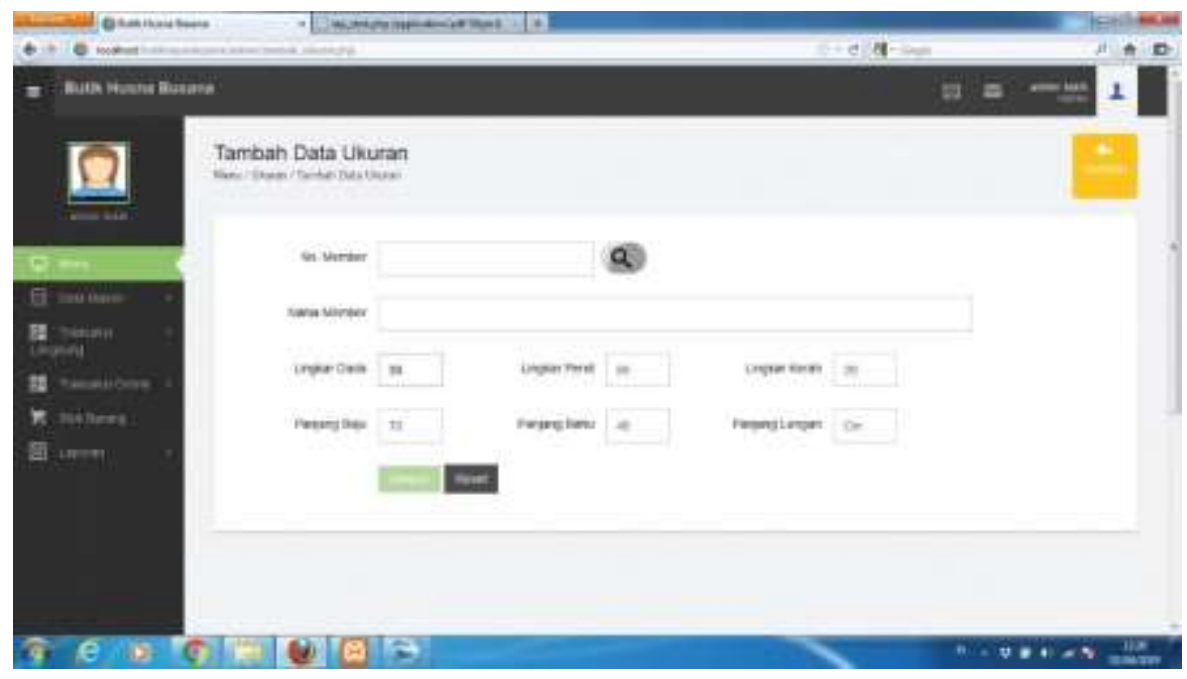

Gambar 4. Form Data Ukuran

Pada form data ukuran ini kelanjutan pendaatan ukuran pelanggan yang mana data ukuran tersebut digunakan untuk pembuatan pakaian yang dipesan oleh pelanggan. 


\section{Tampilan Pemesanan Online}

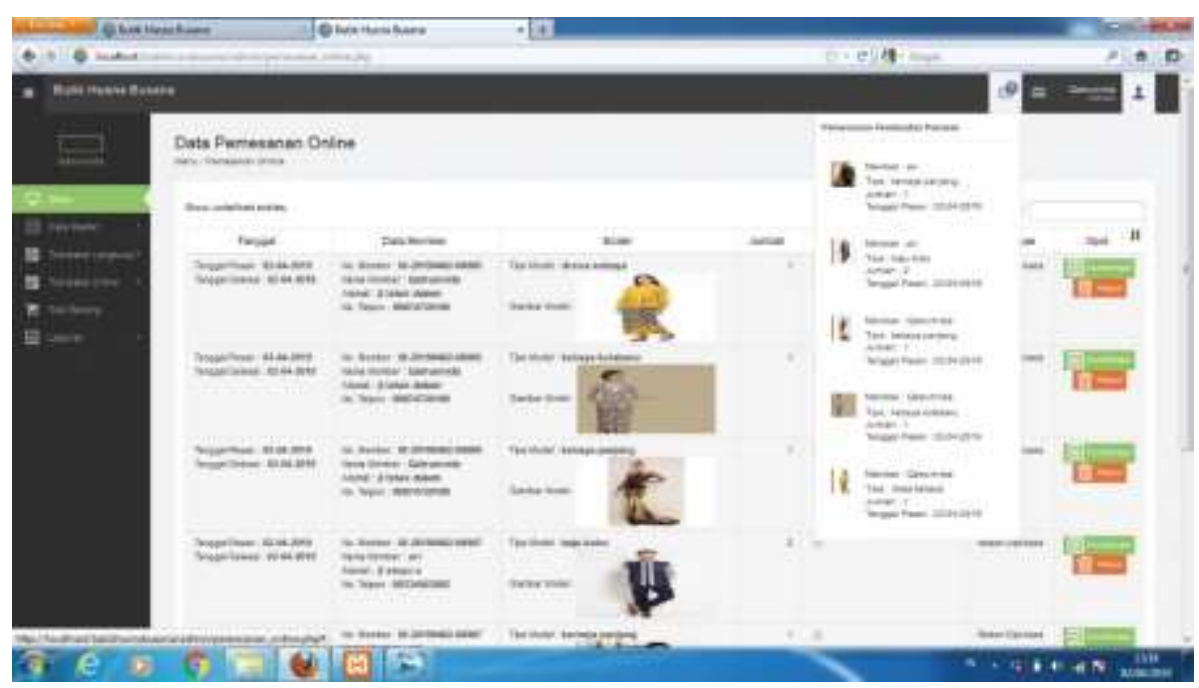

Gambar 5. Data Pemesanan Online

Pada pemesanan online ini data bisa di isi oleh pelanggan sendiri dengan menginput data tipe model dan gambar model pakaian yang di ingkan untuk pembuatan pakaian. Pada form admin terdapat notifikasi pemesanan pelanggan agar admin mengkonfirmasi pemesanan oleh pelanggan sudah bisa diproses.

\section{Riwayat Pemesanan Pembuatan Pakaian}

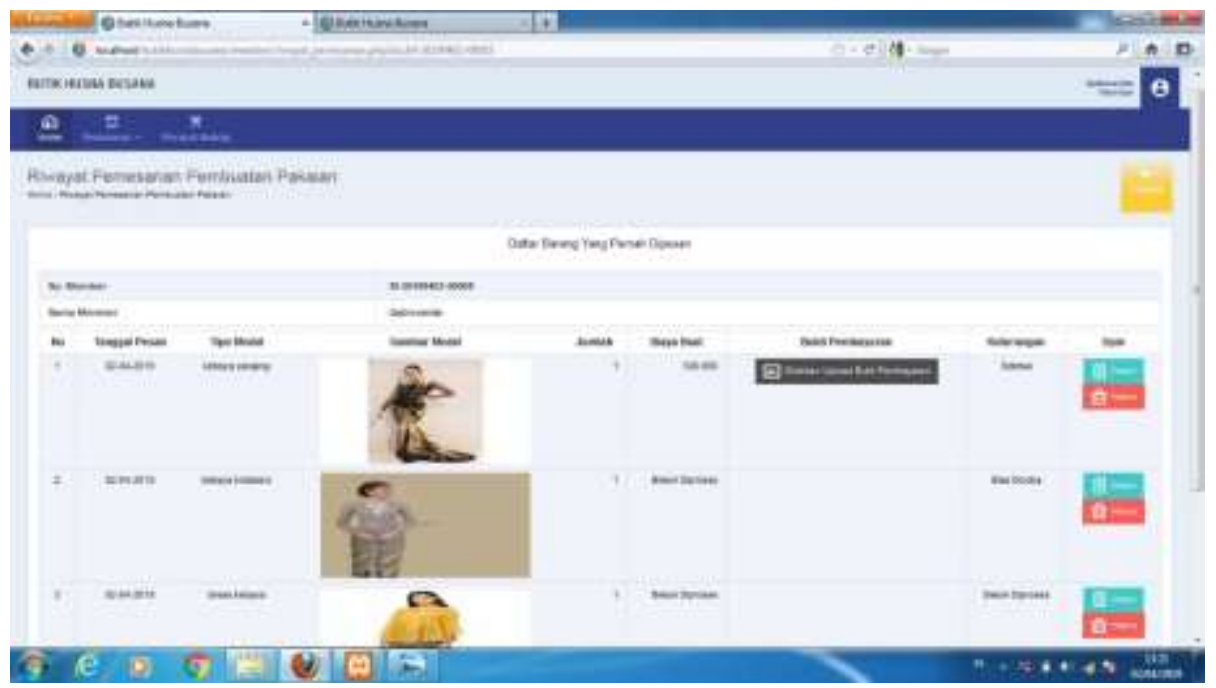

Gambar 6. Riwayat Pemesanan Pembuatan Pakaian

Pada form riwayat pemesanan terdapa progres pembuatan pakaian yang dibagi dengan 4 (empat) status progres, belum diproses, belum selesai, bisa dicoba serta selesai. Apabila telah selesai pembayaran bisa dilakukan menggunakan transfer atau cash, apabila transfer bisa melampirkan bukti transfer pada sistem dikolom bukti pembayaran. 


\section{KESIMPULAN}

Berdasarkan hasil dari pembuatan sistem informasi jasa pembuatan pakaian menggunakan algortima pemprograman terstruktur, dapat ditarik kesimpulan, kesimpulan tersebut yaitu :

1. Rancang bangun aplikasi sistem informasi jasa pembuatan pakaian dengan algoritma pemprograman terstruktur dapat mebuat pendataan palanggan dan pencarian data pelanggan secara cepat.

2. Penginformasian mengenai status progres pembuatan pakaian dapat dilihat langsung melalui website sistem informasi dengan adanya pemberitahuan berupa notifikasi.

3. Pengolahan pendataan sistem pelayanan pada butik husna busana dari pencatatan pembukuan berubah ke sistem berbasis komputer lebih efektif dan efisien dalam hal proses transaksi sistem informasi pada butik husna busana.

\section{DAFTAR PUSTAKA}

[1] A.S, Rosa. M. Shalahudin. (2015, September). Rekayasa Perangkat Lunak

[2] Amin, M. (2019). IMPLEMENTASI APLIKASI MENU PADA RESTORAN JAPANESE FOOD KENZO BENTO BANJARMASIN. Technologia: Jurnal IImiah, 10(1), 34-39.

[3] Alatas, Husein. (2015). Proyek Membangun Responsive Web Design dengan Bootstrap 3\&4. Yogyakarta. C.V Lokomedia.

[4] Ladjamudin, Al-Bahra. 2005. Analisis dan Desain Sistem Informasil. Yogyakarta. Graha Ilmu

[5] Maulani, J. (2016). REKRUTMEN KARYAWAN CV. ANNISA MENGGUNAKAN APLIKASI TEST PISIKOTES DAN KEPRIBADIAN BERBASIS DELPHI. Technologia: Jurnal IImiah, 7(2)

[6] Pratama, I Putu Agus Eka. 2013. Sistem Informasi dan Implementasinya. Bandung. Informatika Bandung

[7] Pranata, Antony. 2005. Algoritma dan Pemrograman. Yogyakarta. J \& J Learning

[8] Rustamaji, A., Rinartha, K., \& Adnyana, I. M. B. (2015). SISTEM INFORMASI JASA PENJAHIT BERBASIS WEB DAN
SMS GATEWAY PADA ATAAHAIFA TAILOR. JOSINFO: Jurnal Online Sistem Informasi, 2(1).

[9] Subekti, M. (1997). Sistem manajemen Basis Data. Jakarta: Universitas Bina Nusantara.

[10] Suarga. M.Math. 2012. Algoritma dan Pemrograman. Yogyakarta. C.V Andi Offset

[11] Setiawan, A., Muin, A. A., \& Ramadhani, B. (2019). PERANCANGAN SISTEM RESERVASI GEDUNG DAN AULA BERBASIS WEB DI WILAYAH BANJARMASIN. Technologia: Jurnal IImiah, 10(1), 1-4.

[12] Terstruktur dan Berorientasi Objek. Bandung. Informatika 